\title{
Проектирование широкополосных скоростных когерентных DWDM-линий связи
}

\author{
P.3. Ибрагимов ${ }^{1,2}$, В.А. Конышев ${ }^{1}$, О.Е. Наний ${ }^{1,3}$, \\ В.Н. Трещиков ${ }^{1,4}$, Р.Р. Убайдуллаев ${ }^{1}$ \\ ${ }^{1} \mathrm{OOO} « \mathrm{~T} 8 \mathrm{HTЦ»}$ \\ ${ }^{2}$ Сибирский государственный университет телекоммуникации и информатики \\ ${ }^{3}$ МГУ им. М. В. Ломоносова \\ ${ }^{4}$ Институт радиотехники и электроники им. В. А. Котельникова РАН, Фрязинский филиал \\ *E-mail: ibragimov.nsk@gmail.com
}

DOI:10.31868/RFL2018.218-219

Актуальной задачей на сегодня является задача увеличения пропускной способности оптической линии для обеспечения потребностей рынка в объемах передаваемой информации. Наиболее привлекательными методами увеличения пропускной способности оптических линий связи при сохранении существующей кабельной инфраструктуры являются использование многоуровневых форматов модуляции и когерентные системы передачи данных совместно со спектральным уплотнением DWDM-каналов [1,2].

Когерентные системы связи с дополнительной цифровой обработкой сигналов на сегодняшний день имеют доминирующее положение в оптических системах связи высокой емкости, так как позволяют обеспечить максимальную спектральную эффективность [1 - 6].

В работах [3, 7, 8] была продемонстрирована возможность увеличения пропускной способности при использовании усилителей $\mathrm{C}$ и $\mathrm{L}$ диапазона. Возможность использования сверхширокополосных висмут-эрбиевых усилителей с полосой усиления более 200 нм описана в работе [9].

В настоящей статье исследован вопрос максимальной пропускной способности многопролетной DWDM-линий при использовании такой большой полосы усиления волоконными усилителями на промежуточных узлах. С помощью феноменологической модели, оценивающей работоспособность оптической DWDM-линии, произведен расчет суммарного влияния шумов в протяженной линии. Для многоканальной системы проведена оптимизация мощности оптического сигнала по критерию максимизации $O S N R_{M}$ и $O S N R_{B E R}$ с учетом энергетического запаса, требуемого для коммерческих DWDM-линий. На основе полученных результатов построены зависимости для оптической полосы 40 нм (сегодняшние DWDM-линии) и 200 нм (DWDM-линии будущего), рисунок 1.

Расчет показывает, что при увеличении полосы усиления группового сигнала емкость такой системы увеличивается практически в пять раз. При этом, максимальная дальность системы составляет 7900 км для полосы в 200 нм. Таким образом, переход от полосы усиления 40 нм к полосе 200 нм резко увеличивает емкость всей системы в целом - особенно сильно это о происходит в случае DWDM-линий с малым числом пролетов. 


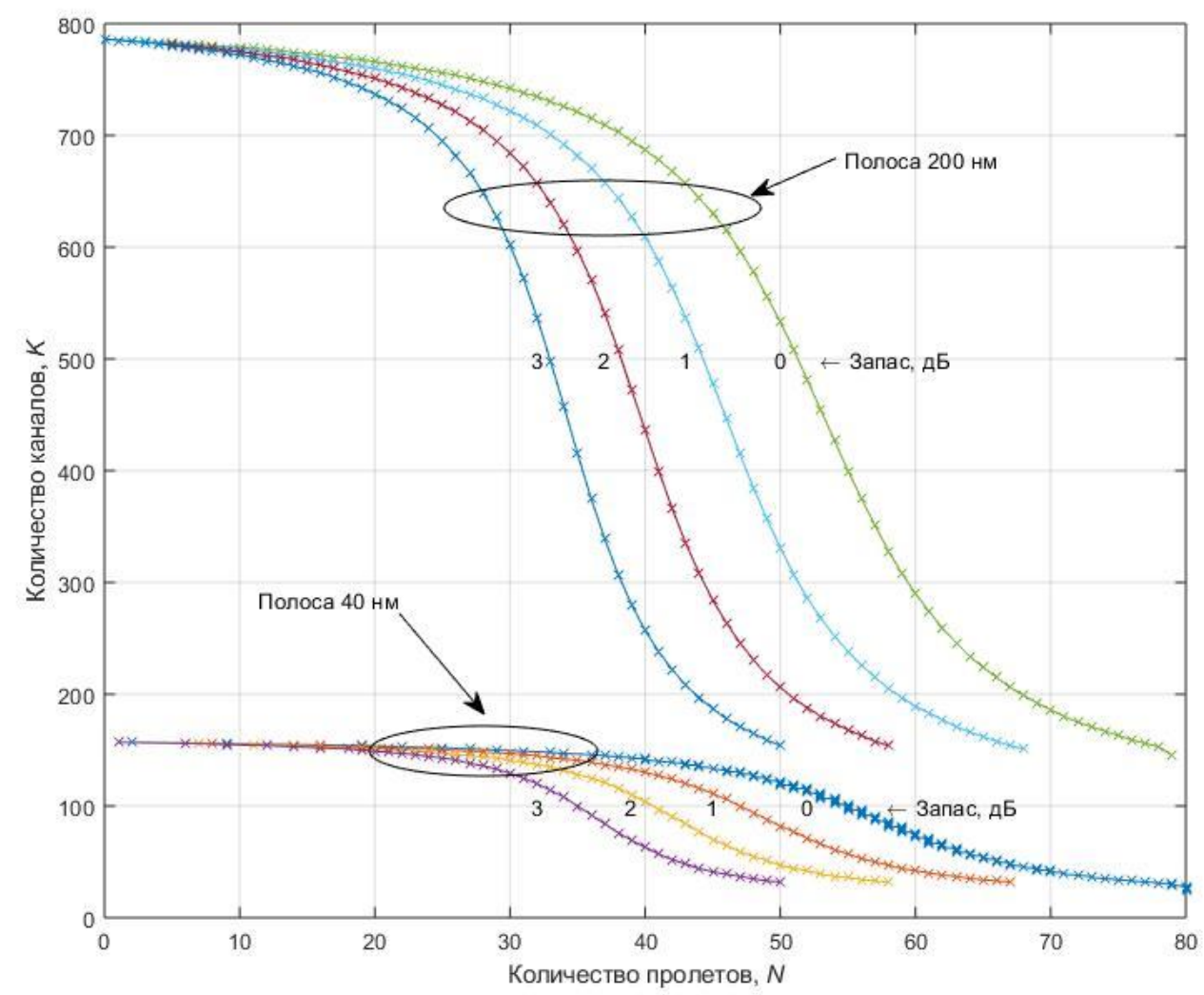

Рис.1 Зависимость максимального количества каналов от протяженности оптической линии

\section{Литература}

[1] Леонов А., и др. Прикладная фотоника. Т. 3. №2. С. 123-145. (2016)

[2] Трещиков В. Фотон-экспресс №3. С. 31-35. (2013)

[3] Гуркин Н., Наний О., Новиков А., Трещиков В. Вестник связи. №8. С. 25-27 (2012).

[4] Гуркин Н. В. [и др.] Квантовая электроника. Т. 43. - №6. С. 550-553 (2013).

[5] Xia C., van den Borne D. Optical Fiber Communication Conference and Exposition (OFC/NFOEC), 2011 and the National Fiber Optic Engineers Conference 2011: IEEE. - pp. 1-3.

[6] Xie C. IEEE Photonics Technology Letters. T. 21. №5. C. 274-276 (2009)

[7] Konyshev V. А. и др. Quantum Electronics. T. 47. №8. С. 767 (2017).

[8] Gainov V. и др. Laser Physics Letters. T. 10. №7. С. 075107 (2013).

[9] Firstov S. V. и др. Optical Fiber Communication Conference 2017: Optical Society of America. pp. W2A. 22. 